\title{
Time constant/volume relationship of passive expiration in mechanically ventilated ARDS patients
}

\author{
J. Guttmann*, L. Eberhard*, B. Fabry*, W. Bertschmann*, \\ J. Zeravik**, M. Adolph**, J. Eckart**, G. Wolff**†
}

Time constant/volume relationship of passive expiration in mechanically ventilated ARDS patients. J. Guttmann, L. Eberhard, B. Fabry, W. Bertschmann, J. Zeravik, M. Adolph, J. Eckart, G. Wolff. C ERS Journals Ltd 1995.

ABSTRACT: Since the adult respiratory distress syndrome (ARDS) lung is known to be inhomogeneous, one could expect an uneven distribution of expiratory time constant during uninterrupted mechanical ventilation. We investigated the time constant/volume relationship of passive expiration, and their modification by external resistive elements.

In 12 paralysed intubated ARDS patients, we determined the expiratory time constant $(\tau E)$ as a function of the expired volume $\left(V_{E}\right)$ during uninterrupted mechanical ventilation. Mean expiratory time was $2.9 \pm 0.3 \mathrm{~s}( \pm \mathrm{SD})$. VE was divided into five equal volume slices (portions) and a mean $\tau \mathrm{E}$ calculated from the expiratory tidal volume/flow curve for each slice.

The mean values of $\tau \mathrm{E}$ for each volume slice did not differ significantly throughout expiration, averaging $690 \pm 218 \mathrm{~ms}$ (mean \pm SD of five slices and 12 patients). We show that the flow-dependent resistance of the endotracheal tube (RETT) is mainly responsible for the observed time constant homogeneity.

We conclude that in ARDS patients during uninterrupted mechanical ventilation the time constants of passive expiration are markedly modified by the flow-dependent resistance of the endotracheal tube (RETT), and also by the external resistance of tubing and ventilator (REX). RETT and REX render $\tau_{\mathrm{E}}$ about three times larger than the time constant of the patient's respiratory system alone.

Eur Respir J., 1995, 8, 114-120.
*Clinical Physiology, Clinic for Cardiac and Thoracic Surgery, Dept of Surgery, University of Basel, Basel, Switzerland. **Dept of Anesthesia and Surgical Intensive Care Medicine, Central Hospital Augsburg, Augsburg, Germany.

Correspondence: J. Guttmann

Sektion für Experimentelle Anaesthesiologie Anaesthesiologische Universitätsklinik Freiburg

Breisacherstrasse 60

D-79106 Freiburg, Germany

Keywords: Endotracheal tube flow-dependent resistance passive expiration tidal volume/flow curve time constant

time constant/volume function

Received: July 151993

Accepted after revision September 91994

Supported by the Swiss National Science Foundation Grant No. 3200 - 39382.93.
The time constant of passive expiration $(\tau \mathrm{E})$ contains information about the mechanical properties of the respiratory system [1]. The slope of the expiratory tidal volume/flow curve reflects $\tau_{\mathrm{E}}[2]$. This is the principle behind the "single-breath" method for the analysis of respiratory system mechanics as applied to anaesthetized animals [3], and to humans [4]. The method is based on the assumption that passive expiration is monoexponential, i.e. that expiration can be described by a single compartment of constant elastance (single volume) emptying itself through a pathway of constant resistance (single resistance).

However, intrinsic characteristics of the lung tissues are viscoelasticity [5], as well as nonlinearity of compliance and resistance [6], and, in addition, the seriously diseased lung, as in adult respiratory distress syndrome (ARDS), shows mechanical inhomogeneity [5]. Each of these factors has an impact on $\tau \mathrm{E}$. Furthermore, under mechanical ventilation $\tau \mathrm{E}$ is not simply the product of resistance and compliance of the patient's respiratory sys-

\footnotetext{
t: Prof. G. Wolff died unexpectedly on Oct. 24 1994. The authors acknowledge him as a pioneer in the field of intensive medicine, notably in the field of mechanical ventilation, and regret the loss of their academic mentor and a scientist of the highest calibre. They express their commitment to the continuance of his scientific work.
}

tem, but also depends on additional resistive elements, such as the endotracheal tube (ETT), ventilator tubing and the expiratory valve $[7,8]$. Since ETT resistance (RETT) is markedly flow-dependent $[9,10]$, $\tau$ E must be expected to be flow-dependent, also. The flow-dependent RETT, as well as the mechanical inhomogeneity and nonlinearity of lung mechanics, could be expected to cause a time constant inhomogeneity of the early fast component of expiration in ARDS. The early fast component of expiration must be distinguished from the very late and slow component of expiration probably caused by viscoelasticity, as found in animals by BATES et al. [11], and in patients with normal lungs and with ARDS by CHelucci and co-workers [12, 13]. However, against all expectations, we have hardly ever observed an indication of time constant inhomogeneity of the fast component of passive expiration in the large number of expiratory volume/flow $(\mathrm{V} / \mathrm{V})$-curves that we have obtained from ARDS patients. This contradiction between expectations and observations stimulated us to investigate passive expiration in ARDS under mechanical ventilation in greater detail.

At any given time during expiration, $\tau \mathrm{E}$ is modified by the patient's respiratory system mechanics, by the mechanics of the ETT, and by the tubing and valves of the 
ventilator. Our understanding of respiratory system mechanics is based on mathematical models of varying complexity "with behaviour that should mimic that of the real system and whose parameters should have a physiological meaning" [5]. However, external components, such as the ETT, tubing and valves are usually not modelled.

In this study, we extended the linear resistance-capacitance (RC) model to include these external components, and we present a new method of analysing passive expiration, which allows us to describe the entire chain of the respiratory system (patient, ETT and ventilator). The expired volume is divided into a series of consecutive volume slices (portions), and a mean $\tau \mathrm{E}$ is determined separately for each slice. Passive expiration is interpreted as a sequential process, where the volume slices are exhaled one after another, i.e. each volume slice is exhaled with its individual time constant. The relationship between $\tau \mathrm{E}$ and expired volume describes the expiratory process.

The purpose of this study was to investigate the time constant/volume relationship of the fast component of passive expiration by analysing the expiratory flow signal in intubated and relaxed ARDS patients under conditions of uninterrupted mechanical ventilation.

\section{Patients and methods}

We investigated 12 patients mechanically-ventilated for severe adult respiratory distress syndrome (ARDS) after polytrauma and/or sepsis (definition according to RALPH et al. [14]). Clinical data are listed in table 1. The mean lung injury score computed according to MurRay et al. [16] was $>2.5$, indicating a severe degree of acute lung injury in all patients. The duration of mechanical ventilation preceding the investigation was, on average, 6 days. The ventilatory parameters are given in table 2. All patients were ventilated in the volume controlled mode with constant inspiratory flow using the EV-A ventilator (Dräger, Lübeck, FRG). All patients were tracheally intubated either with an endotracheal tube (ETT) of $7.5 \mathrm{~mm}$ internal diameter (ID) (one patient), or an ETT of $8.0 \mathrm{~mm}$ ID (eight patients), or with a tracheostomy tube of $9.0 \mathrm{~mm}$ ID (three patients). Under adequate analgesia and sedation, the patients were paralysed (pancuronium bromide (Pavulon ${ }^{\circledR}$ ), $0.1 \mathrm{mg} \cdot \mathrm{kg}^{-1}$ body weight (BW), $30 \mathrm{~min}$ before the start of the investigation, followed by additional administrations of 0.05 $\mathrm{mg} \cdot \mathrm{kg}^{-1}$ BW every $\left.60 \mathrm{~min}\right)$. All measurements were taken with the patients in a supine position, and under steady-state conditions. The study was approved by the Hospital Ethics Committee.

Flow $(\dot{V})$ and airway pressure (Paw) were measured at the outer end of the endotracheal tube. Gas flow was measured with a heated Fleisch No. 2 pneumotachograph (Metabo, Epalinges, $\mathrm{CH}$ ) connected to a differential pressure transducer FC040 (Furness Controls, Bexhill, UK), airway pressure with a pressure transducer SZ75120 (Sensym, UK). The sensors were connected to the measuring site through three silicone tubes $(180$

Table 1. - Clinical course of ARDS patients preceding the investigation

\begin{tabular}{|c|c|c|c|c|c|c|c|}
\hline No. & Sex & $\begin{array}{l}\text { Age } \\
\text { yrs }\end{array}$ & Clinical course & APV,rel & $\begin{array}{l}\text { Lung } \\
\text { injury } \\
\text { score* }\end{array}$ & $\begin{array}{c}\text { Days } \\
\text { after } \\
\text { intubation }\end{array}$ & Outcome \\
\hline 1 & M & 79 & $\begin{array}{l}\text { Laparotomy for bleeding ventricular ulcer, bronchopneumonia, } \\
\text { septicaemia, MOF, ARDS }\end{array}$ & 92 & 2.8 & 3 & Died \\
\hline 2 & M & 60 & $\begin{array}{l}\text { Multiple trauma with brain damage, laparotomy and trepanation, } \\
\text { haemorrhagic shock, acute respiratory failure, ARDS }\end{array}$ & 59 & 2.5 & 3 & Discharged \\
\hline 3 & M & 75 & $\begin{array}{l}\text { Abdomino-peritoneal resection of the rectum for rectal carcinoma, } \\
\text { relaparotomy for volvulus, aspiration, ARDS }\end{array}$ & 65 & 2.8 & 10 & Died \\
\hline 4 & $\mathrm{~F}$ & 56 & $\begin{array}{l}\text { Laparotomy for bleeding ventricular ulcer, bronchopneumonia, } \\
\text { septicaemia, ARDS }\end{array}$ & 62 & 3.0 & 10 & Discharged \\
\hline 5 & M & 50 & $\begin{array}{l}\text { Decortication for pleural empyema following chronic osteitis, } \\
\text { septicaemia, ARDS }\end{array}$ & 68 & 2.5 & 2 & Discharged \\
\hline 6 & M & 73 & $\begin{array}{l}\text { Coronary artery bypass graft, aortic balloon pumping, cholecy- } \\
\text { stectomy for acute cholecysitis, bronchopneumonia, MOF, ARDS }\end{array}$ & 38 & 3.0 & 7 & Died \\
\hline 7 & M & 64 & $\begin{array}{l}\text { Chest wall resection for chondrosarcoma, bronchopneumonia, } \\
\text { septicaemia, ARDS }\end{array}$ & 58 & 2.8 & 7 & Died \\
\hline 8 & M & 79 & $\begin{array}{l}\text { Hemicolectomy for colon carcinoma, relaparotomy for peritonitis, } \\
\text { bronchopneumonia, septicaemia, MOF, ARDS }\end{array}$ & 51 & 2.5 & 2 & Died \\
\hline 9 & M & 65 & $\begin{array}{l}\text { Cholecystectomy for gall bladder perforation, peritonitis, } \\
\text { bronchopneumonia, ARDS }\end{array}$ & 31 & 2.5 & 4 & Discharged \\
\hline 10 & M & 47 & $\begin{array}{l}\text { Multiple trauma, fracture of vertebral column, bowel resection, } \\
\text { septicaemia, ARDS }\end{array}$ & 38 & 3.0 & 8 & Discharged \\
\hline 11 & M & 33 & $\begin{array}{l}\text { Multiple trauma, haemorrhagic shock, acute respiratory failure, } \\
\text { ARDS }\end{array}$ & 34 & 3.0 & 8 & Died \\
\hline 12 & M & 59 & $\begin{array}{l}\text { Three laparotomies for recurrent bleeding ventricular ulcer, } \\
\text { haemorrhagic shock, bronchopneumonia, septicaemia, MOF, ARDS }\end{array}$ & 57 & 3.0 & 12 & Died \\
\hline
\end{tabular}

*: according to MurRaY et al. [16], including the respiratory system compliance score. APV,rel: accessible pulmonary volume in \% of expected FRC [15] (sitting posture), determined by nitrogen wash-out; ARDS: adult respiratory distress syndrome; MOF: multiple organ failure, Pat: patient; $\mathrm{M}$ : male; F: female; FRC: functional residual capacity. 
Table 2. - Mean respiratory data of the patients

\begin{tabular}{|c|c|}
\hline$\dot{\mathrm{V}} \mathrm{CO}_{2} \quad \mathrm{ml} \cdot \mathrm{min}^{-1}$ & $234 \pm 42$ \\
\hline Alv.eff- $\mathrm{CO}_{2} \% *$ & $65 \pm 7$ \\
\hline$f_{R}$ breaths $\cdot \min ^{-1}$ & $15 \pm 2$ \\
\hline $\mathrm{V}_{\mathrm{T}} \mathrm{ml} \dagger$ & $989 \pm 103$ \\
\hline$\dot{\mathrm{V}}_{\mathrm{E}} l \cdot \mathrm{min}^{-1} \dagger$ & $14.3 \pm 1.4$ \\
\hline$f_{\mathrm{R}} \cdot \operatorname{VDS} \quad l \cdot \mathrm{min}^{-1} \dagger$ & $3.8 \pm 0.7$ \\
\hline $\mathrm{Crs} \mathrm{ml} \cdot \mathrm{cmH}_{2} \mathrm{O}^{-1}$ & $50 \pm 15$ \\
\hline $\operatorname{Rrs} \quad \mathrm{cmH}_{2} \mathrm{O} \cdot \mathrm{s} \cdot l^{-1}$ & $9.6 \pm 1.7$ \\
\hline Q்s/Q \% & $22 \pm 7$ \\
\hline TE $\mathrm{s}$ & $2.1 \pm 0.3$ \\
\hline PEEP $\mathrm{cmH}_{2} \mathrm{O}$ & $11.4 \pm 2.6$ \\
\hline $\mathrm{Paw}, \mathrm{max} \quad \mathrm{cmH}_{2} \mathrm{O}$ & $42 \pm 7$ \\
\hline $\mathrm{FIO}_{2}$ & $0.6 \pm 0.01$ \\
\hline $\mathrm{PaO}_{2} \mathrm{kPa}$ & $14.7 \pm 5.5$ \\
\hline
\end{tabular}

The data from 12 patients (reference ventilation pattern) are presented as mean \pm SD. All volumes are given in BTPS. $\dot{\mathrm{V}}_{\mathrm{CO}_{2}}$ : $\mathrm{CO}_{2}$ output; Alv.eff- $\mathrm{CO}_{2}$ : alveolar efficiency of $\mathrm{CO}_{2}$ elimination; $\mathrm{FCO}_{2}$-Alv-mean/ $\mathrm{FCO}_{2}$-arterial where $\mathrm{FCO}_{2}$-Alv-mean = $\mathrm{VCO}_{2} /\left(\mathrm{V}_{\mathrm{T}}-\mathrm{V}_{\mathrm{DS}}\right) ; f_{\mathrm{R}}$ : respiratory frequency; $\mathrm{VT}$ : tidal volume; VE: expiratory minute ventilation; VDS: series dead space volume; Crs: total respiratory system compliance; Rrs: total respiratory system resistance, including endotracheal tube resistance; $\mathrm{Q}$ s/Q: pulmonary shunt fraction; TE: expiratory duration; PEEP: positive end-expiratory pressure; Paw,max: maximal airway pressure; $\mathrm{FIO}_{2}$ : fractional inspiratory oxygen; $\mathrm{PaO}_{2}$ : arterial oxygen tension; $\dagger:$ volume at body temperature and pressure saturated with water vapour. *: method of determination given in [17].

$\mathrm{cm}$ long, $4 \mathrm{~mm}$ ID). We tested the frequency dependence of our equipment, and found a reasonably flat response up to $30 \mathrm{~Hz}$. The signals were filtered at a cut-off frequency of $27 \mathrm{~Hz}$. To correct the flow for changes in gas viscosity, dry gas fractions were measured using a quadrupole mass spectrometer MGA-200 (Centronic, Croydon, UK), connected by a $3.5 \mathrm{~m}$ long, $0.38 \mathrm{~mm}$ ID PP20 polyethylene capillary (Portex, Hythe, Kent, UK). The analogue flow, pressure and gas concentration signals were sampled $(60 \mathrm{~Hz})$, digitized $(12 \mathrm{bit})$ and stored for off-line analysis. Volume was determined by numeric integration of the flow signal. To characterize the patient's respiratory system, accessible pulmonary gas volume (APV) was determined using the nitrogen washout technique. The details of the wash-out technique including synchronization of flow and concentration signals have been described previously $[18,19]$.

Table 3. - Changes in ventilatory pattern

\begin{tabular}{lcc}
\hline & REF & F+ \\
\hline $\mathrm{n}$ & 12 & 12 \\
$\mathrm{PEEP} \mathrm{cmH}_{2} \mathrm{O}$ & $11.4 \pm 2.6$ & $11.0 \pm 2.4$ \\
$\mathrm{VT} \mathrm{ml}$ & $989 \pm 103$ & $977 \pm 104$ \\
$\dot{\mathrm{V}}_{\mathrm{I} \mathrm{ml} \cdot \mathrm{s}^{-1}}$ & $529 \pm 68$ & $1,026 \pm 116$ \\
$f_{\mathrm{R}} \mathrm{breaths} \cdot \mathrm{min}^{-1}$ & $14.9 \pm 1.7$ & $15.4 \pm 1.6$ \\
$\mathrm{TE} \mathrm{s}$ & $2.1 \pm 0.3$ & $2.9 \pm 0.3$ \\
\hline
\end{tabular}

Data from 12 patients are presented as mean \pm SD. REF: reference ventilation pattern; $\mathrm{F}+$ : ventilation pattern with increased inspiratory flow. PEEP: positive end-expiratory pressure; VT: tidal volume at BTPS; $\dot{V}_{\mathrm{I}}$ : inspiratory flow at BTPS; $f_{\mathrm{R}}$ : respiratory frequency; TE: expiratory duration; BTPS: body temperature and pressure saturated with water vapour.
In each ARDS patient, two different patterns of mechanical ventilation were investigated: the first pattern was the reference ventilation pattern (REF) chosen by the medical team in charge; this pattern was investigated to determine the respiratory data of the patients (table 2). The second pattern was characterized by a long expiratory time $(\mathrm{TE})$ achieved by increasing inspiratory flow (marked as "F+") and avoiding an end-inspiratory pause. The second pattern was investigated to obtain more information on the time course of passive expiration. The modifications and mean ventilatory parameters of 12 patients are listed in table 3 .

After ventilation for $40 \mathrm{~min}$ with the new pattern, patients were assumed to be in a steady-state condition, and data acquisition was started. For each patient and each ventilatory pattern 15 consecutive breaths were analysed and averaged.

Following the procedure of PEPE and MARINI [20], the intrinsic positive end-expiratory pressure (PEEPi) was measured with the end-expiratory occlusion manoeuvre, as described in detail by EBERHARD et al. [21]. The gas volume (VRET) retained by dynamic hyperinflation [22] was determined by numeric integration of the flow expired after the occlusion manoeuvre [21]. For each ventilatory pattern, PEEPi and VRET were averaged from three occlusion manoeuvres. In one patient (No. 7) the assessment of VRET was invalid because of a leakage during the occlusion manoeuvre.

\section{Data analysis}

The $\tau \mathrm{E} / \mathrm{VE}_{\mathrm{E}}$ function was derived in three steps (fig. 1).

Step 1: preparation of data (fig. 1a). The expiratory flow and volume data from 15 consecutive breaths were averaged on a point-by-point basis to eliminate cardiogenic flow oscillations. Volume was plotted against flow. Time constants can only be determined for that part of expiration that is potentially exponential. Early expiration up to the inflection point (IP) of the flow curve is predominantly influenced by inertial effects, and, therefore, cannot be analysed using a simple 1st order model; it was therefore excluded from analysis. IP of the averaged expiratory flow curve is defined as the point of maximum slope following the expiratory peak flow. Following the IP, the expiratory flow/time and volume/time curves show an exponential decay. IP was determined by means of a moving window algorithm, including four consecutive flow samples (breath-bybreath reproducibility is \pm 2 samples or $\pm 33 \mathrm{~ms}$, respectively). The expired volume in the averaged expiratory volume/flow curve (from IP to the end of expiration) was subdivided into five consecutive slices ( $i=1 \ldots .5)$ of equal size. The number of slices was chosen as a compromise between high resolution on the volume axis and low disturbance due to signal noise.

Step 2: calculation of $\tau_{E}$ (fig. 1 b). Within each volume slice, the respiratory system with compliance Crs and resistance Rrs in conjunction with the flow-dependent 
resistance of the endotracheal tube RETT(V) and the external resistance of the ventilator's expiratory tubing and valve Rex can be appropriately described by the differential equation:

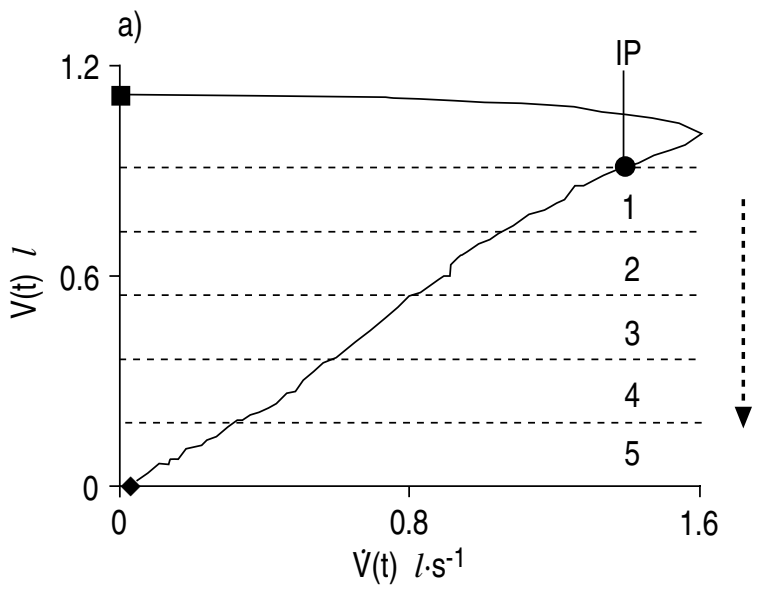

b)

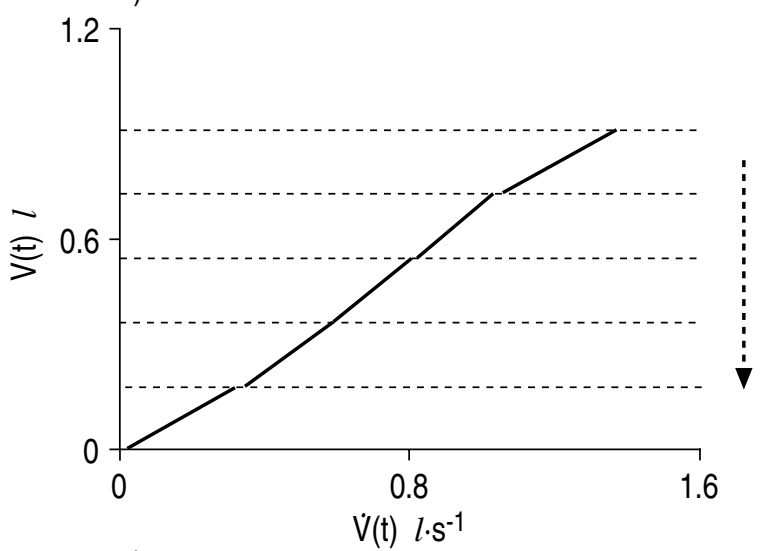

c)

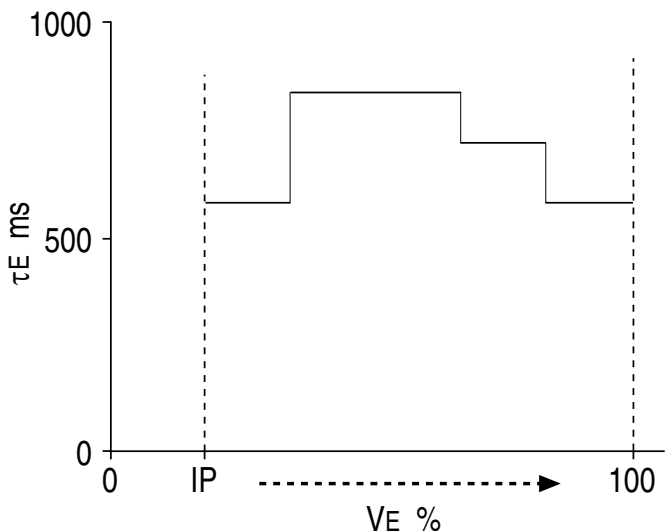

Fig. 1. - a) Step 1: Expiratory volume/flow curve $(\mathrm{V}(\mathrm{t}) / \mathrm{V}(\mathrm{t})$ ) (patient No. 3) using values averaged from 15 breaths. Expiration starts at the end-inspiratory volume ( $\mathbf{\square})$, and is finished with the end-expiratory flow $\left(\mathrm{VE}^{\prime}\right)(\bullet)$ being the flow at the end of expiration. 'VE' was 0.019 $l \cdot \mathrm{s}^{-1}$ in this patient. Starting at the inflection point (IP) (•) the expired volume is subdivided into five slices $(i=1 \ldots 5)$ of equal size. b) Step 2: For each slice, $i$, the volume/flow curve is substituted by a fitted straight line (least-squares fit). The slope of each straight line gives the expiratory time constant $\tau \mathrm{E}$ i of the corresponding volume slice. c) Step 3: Plot of the expiratory time constant ( $\tau E)$ versus expired volume $(\mathrm{VE})$. We call this plot the $\tau_{\mathrm{E}} / \mathrm{VE}_{\mathrm{E}}$ function. The dashed arrows show the sequential process of expiration from IP to the end of expiration.

$$
\mathrm{V}(\mathrm{t}) / \mathrm{Crs}+\mathrm{V}(\mathrm{t}) \times \operatorname{Rrs}+\dot{\mathrm{V}}(\mathrm{t}) \times(\operatorname{RETT}(\dot{V})+\operatorname{REX})=0
$$

where $\mathrm{V}(\mathrm{t})$ is flow, and $\mathrm{V}(\mathrm{t})$ is volume above functional residual capacity (FRC). Equation (1) means that the driving pressure for passive expiration, i.e. the elastic recoil pressure, equals the total resistive pressure drop. If we assume that RETT is constant during the exhalation of each volume slice, the flow, $\mathrm{V}(\mathrm{t})$, as a solution of equation (1) follows an exponential decay curve with the time constant $\tau \mathrm{E}$ :

$$
\tau \mathrm{E}=(\operatorname{Rrs}+\operatorname{ReTT}(\mathrm{V})+\operatorname{ReX}) \times \mathrm{Crs}
$$

Since $\tau$ E equals the derivative $\mathrm{dV} / \mathrm{dV}$ [2], it can be directly read as the slope of the $\mathrm{V} / \mathrm{V}$-curve. In our method, we determine one representative $\tau$ Ei for each slice as the slope of straight lines fitted to the $\mathrm{V} / \dot{\mathrm{V}}$-curve within each slice (least-squares fit).

Step 3: graphic presentation of the results (fig. 1c). Finally $\tau$ Ei is plotted against the expired volume giving the $\tau \mathrm{E} / \mathrm{VE}$ function.

\section{Statistical analysis}

Statistical independence of $\tau \mathrm{E}$ from VE was tested using the Spearman rank correlation test; $\mathrm{p}<0.01$ was accepted as statistically significant. The test was performed for each patient separately, as well as for the interindividual mean values of $\tau \mathrm{E}$.

\section{Results}

Figure 2 shows the $\tau \mathrm{E} / \mathrm{VE}$ function averaged from all 12 ARDS patients for each of the five volume slices expired after the inflection point. The mean expiratory time constant of all volume slices was $690 \mathrm{~ms}$. The mean standard deviation of all volume slices was \pm 218 ms. In 10 out of 12 patients the Spearman rank correlation test revealed $\tau \mathrm{E}$ to be statistically independent from VE. In one patient, $\tau$ E increased steadily from 450 to $1,170 \mathrm{~ms}$, thus giving a positive correlation. In one

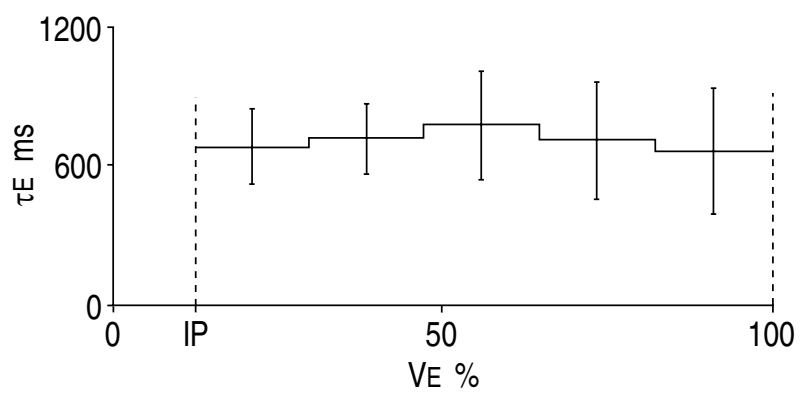

Fig. 2. - Expiratory time constant ( $\tau \mathrm{E})$ versus expired volume $(\mathrm{VE})$ : $\tau \mathrm{E} /$ VE function. Results of 12 mechanically-ventilated ARDS patients are averaged. Each horizontal bar represents the $\tau \mathrm{E}$ of the corresponding volume slice averaged from 12 patients; vertical bars give standard deviations. The mean expiratory time constant over all volume slices was $690 \mathrm{~ms}$. Mean VE is defined as $100 \%$. ARDS: adult respiratory distress syndrome; IP: inflection point. 
Table 4. - Parameters quantifying the incompleteness of expiration

\begin{tabular}{ccc}
\hline $\begin{array}{c}\dot{\mathrm{V}}^{\prime} \\
\mathrm{ml} \cdot \mathrm{s}^{-1}\end{array}$ & $\begin{array}{c}\text { dPEEPi* } \\
\mathrm{CmH}_{2} \mathrm{O}\end{array}$ & $\begin{array}{c}\text { VRET } \\
\mathrm{ml}\end{array}$ \\
\hline $25 \pm 23$ & $1.0 \pm 1.0$ & $42 \pm 27$ \\
\hline
\end{tabular}

Data from 12 patients are presented as mean \pm SD. VRET (BTPS) is averaged from 11 patients ( $\mathrm{F}+$ ventilation pattern). VE': endexpiratory flow (BTPS); dPEEPi: difference between the intrinsic PEEP and the external PEEP; VRET: volume retained due to dynamic hyperinflation. *: measured by means of the endexpiratory occlusion manoeuvre. For abbreviations see legend to table 3 .

patient, $\tau$ E decreased steadily from 510 to $300 \mathrm{~ms}$, thus giving a negative correlation. The interindividual $\tau \mathrm{E}$ mean values averaged from 12 patients were statistically independent from VE.

The parameters which characterize the incompleteness of expiration are summarized in table 4 . The mean endexpiratory flow was $25 \mathrm{ml} \cdot \mathrm{s}^{-1}$; the difference between the PEEPi and the external PEEP set at the ventilator was $1.0 \mathrm{cmH}_{2} \mathrm{O}$; and the dynamically retained volume was $42 \mathrm{ml}$. This indicates that expiration was nearly complete, i.e. at the time the next inspiration started, more than $95 \%$ of the volume which can possibly be expired was already exhaled. There is, consequently, no indication of relevant incompleteness of expiration.

\section{Discussion}

The main result of this investigation was that consecutive volume portions were exhaled with nearly identical time constants of only about $700 \mathrm{~ms}$ in intubated ARDS patients during continuous, i.e. uninterrupted mechanical ventilation (fig. 2). This finding was surprising in the light of present knowledge about ARDS, including the computed tomographic (CT) scan studies which have confirmed that the ARDS lung is very inhomogeneous [23]. Based on these publications and on our own observations of slow pressure changes during zero-flow manoeuvres, we had expected a distribution of expiratory time constants with very small $\tau \mathrm{E}$ values at the beginning of expiration.

To prevent our expectations from becoming an inherent part of the method, we used a new analysis describing expiration in mechanically-ventilated patients as a sequential process, i.e. the expiratory volume is exhaled in sequential slices (portions). The combination of all mechanical influences on $\tau \mathrm{E}$, exerted by the patient's respiratory system as well as by the ETT and the ventilator, changes with the position on the recoil pressure/volume curve, i.e. $\tau \mathrm{E}$ changes during expiration. We extended the classic linear RC-model by including the flow-dependent resistance of the endotracheal tube (RETT $(\dot{V}))$ and the resistance of the ventilator tubing and expiratory valve (REx). We subdivided the expiratory volume following the inflection point in the $\mathrm{V} / \mathrm{V}$-curve into five slices and applied our modified model to each slice separately, or in other words, we confined the range of validity of this model to a small slice of passively expired volume. $\operatorname{RetT}(\dot{V})$ is assumed to be constant within each slice and the time constant of each slice, i, can thus be determined as the slope of a fitted straight line.

The fast component of expiration is driven by the elastic recoil of the respiratory system, which depends on the state of inflation, i.e. on the pulmonary gas volume. Each $\tau$ Ei therefore characterizes the respiratory system at a different volume. Since the fast component of expiration is responsible for the main part of expired volume, the expiratory $\mathrm{V} / \mathrm{V}$-curve is well-suited for its description, i.e. fast expiration can be described in the volume-domain with the benefit of simple linear fits. In contrast, the slow component of expiration, which is mainly caused by time-consuming processes, such as viscoelasticity, contributes only minimally to the expired volume. The expiratory $\mathrm{V} / \mathrm{V}$-curve is, therefore, not suited for description of slow expiratory processes, which should be analysed in the time-domain as described, e.g. by CHELuCCI and co-workers [12, 13].

We found the time constant of passive expiration in ARDS patients under mechanical ventilation to be nearly unchanged. The mean $\tau \mathrm{E}$ in 12 patients was about $700 \mathrm{~ms}$. The largest $\tau \mathrm{E}$ value found in one patient was 1,170 ms (slice No. 5). Our finding that time constants change little in consecutive volume slices raises the question: why did we not find small time constants in early expiration? In the intubated patient the expiratory time constant $(\tau \mathrm{E})$ is not simply the product of patient resistance and compliance. In addition to the respiratory system there are two more flow resistive elements which contribute to the time constant: the ETT (RETT) and the ventilator tubing (REX), as set out in equation (2).

Figure 2 shows the expiratory time constant, including all resistive components of the expiratory branch as a function of the expired volume. However, in order to determine the relative contribution of REX and RETT to the time constant we need to calculate the volume-dependent time constant from the volume-dependent compliance and resistance of the patient's respiratory system alone. This is achieved by analysing the volume-dependent compliance and resistance within each volume slice. Using the airway pressure measured at the outer end of the endotracheal tube the analysis gives the volumedependent resistance including RETT; using the continuously calculated tracheal pressure [10] the analysis gives the volume-dependent resistance of the respiratory system alone.

We calculated the time constant of the respiratory system with and without RETT. Figure 3 gives a synoptic presentation of the results, including the $\tau \mathrm{E} / \mathrm{VE}-$ function of figure 2. There is a certain restriction to a direct comparison of the three curves of figure 3 , because the compliance and resistance values determined by lung mechanics analysis apply to both inspiration and expiration, and do not, therefore, give a purely expiratory time constant. However, it has recently been shown that inspiratory and expiratory values are practically identical, at least for static compliance [24]. Figure 3 shows that the time constant of the pure respiratory system is 


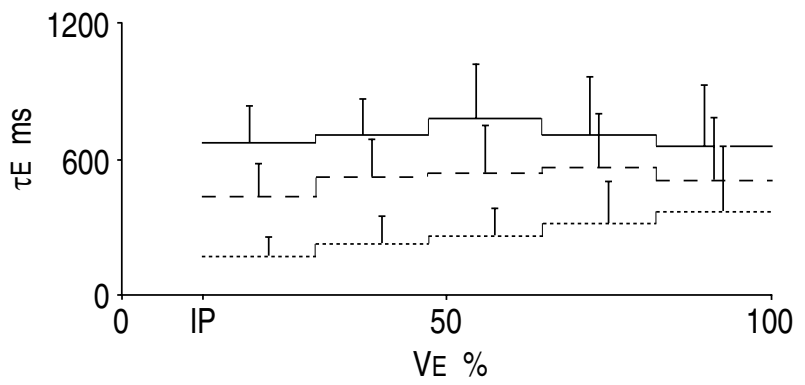

Fig. 3. - Expiratory time constant ( $\tau \mathrm{E}) v s$ expired volume (VE). Results of 12 mechanically-ventilated ARDS patients are averaged (same presentation as figure 2). The lower line represents the time constant of the pure respiratory system calculated as the product of respiratory system resistance times compliance ( $\mathrm{Rrs} \times \mathrm{Crs})$. The middle line represents the time constant of the respiratory system including the resistance of the endotracheal tube (RETT). Note the different shape of both lines. The flow dependent RETT causes a flow-dependent increase of $\tau \mathrm{E}$, thus rendering the $\tau \mathrm{E} / \mathrm{VE}$ function nearly horizontal. The upper line is identical to the $\tau \mathrm{E} / \mathrm{VE}$ function of figure 2, which also includes the external resistance of tubing and ventilator (REX). - : $\quad($ Rrs + RetT + ReX $) \times$ Crs; - - : (Rrs + RetT $) \times$ Crs; ...... Rrs $\times$ Crs. For further abbreviations see legend to figure 2 .

about one third to a half of the "total" time constant (which includes RetT and Rex), and that it increases continuously during expiration. The difference between the lower and the middle line of figure 3 is caused by the flow resistance of the endotracheal tube. As the middle line of figure 3 shows, RETT has a large effect on the time constant in early expiration and a smaller effect in late expiration, thus giving a nearly horizontal course for the time constant. The reason for this is the strong flow-dependency of RETT [9, 10]: if RETT increases with flow, then $\tau$ E also increases with flow. Since flow is maximal at the start of expiration in passive expiration, the contribution of RETT is maximal in early expiration. For example, the mean expiratory peak flow in our patients of $1.55 \pm 0.25 l \cdot \mathrm{s}^{-1}$ (mean $\left.\pm \mathrm{SD}\right)$ would cause a pressure drop of $16 \mathrm{cmH}_{2} \mathrm{O}$ across an ETT with an assumed ID of $8 \mathrm{~mm}$ [10]. Due to the considerable flow-dependency of its resistance, the ETT eliminates small $\tau_{\mathrm{E}} \mathrm{val}-$ ues which would be present in early expiration without an ETT. The contribution of REX to the time constant depends on the ventilatory equipment used (tubing and ventilator). In our equipment, REX was nearly constant (approximately $5 \mathrm{cmH}_{2} \mathrm{O} \cdot \mathrm{s} \cdot l^{-1}$ ); thus, the upper line (which is the same as in figure 2) lies nearly parallel to the middle line.

We investigated ARDS patients under clinical conditions, i.e. under continuous volume-controlled mechanical ventilation without any interruption or manoeuvre. Since in ARDS series dead space volume is augmented and alveolar efficiency for $\mathrm{CO}_{2}$ elimination is reduced [17], minute ventilation would be increased (see table 2). However, in the presence of decreased compliance, a further increase in tidal volume would increase the risk of barotrauma [25]. An increase in respiratory frequency thus cannot be avoided, and therefore the cycle time is reduced. Without changing the inspiratory:expiratory (I:E) ratio the expiratory time would be proportionally reduced. We changed the I:E ratio by increasing the inspiratory flow, thus prolonging the expiratory time. But, our 12 ARDS patients needed a mean expiratory frequency of 15 breaths $\cdot \mathrm{min}^{-1}$, and expiratory time, thus, could hardly be set longer than $\mathrm{TE}=2,900 \pm 300 \mathrm{~ms}$ (mean $\pm \mathrm{SD}$ ). However, the end-expiratory flow was very small (25 $\left.\mathrm{ml} \cdot \mathrm{s}^{-1}\right)$, there was only a little difference between PEEPi and external PEEP $\left(\mathrm{dPEEPi}=1 \mathrm{cmH}_{2} \mathrm{O}\right)$, and the dynamically retained volume $(42 \mathrm{ml}$, or less than $5 \%$ of the volume which could possibly be exhaled) was very small also, all three observations indicating that our ex-piratory time of $3 \mathrm{~s}$ was sufficient for near complete expiration.

$\tau \mathrm{E}$ only increased steadily in one of the patients in the present study, from 450 to $1,170 \mathrm{~ms}$. This could be explained with a parallel slow compartment $[26,27]$ and/ or with viscoelasticity. In common with other authors, we have observed time-consuming pressure equilibration processes in ARDS patients during an end-inspiratory pause $[28,29]$, as well as during an end-expiratory occlusion manoeuvre $[21,30,31]$. Because in our continuously ventilated patients expiratory time could only be increased by reducing inspiratory time and avoiding an end-inspiratory pause, the viscoelastic compartment becomes "occult" [32].

We conclude that in intubated and mechanicallyventilated ARDS patients the time constants of passive expiration are markedly modified by the flow-dependent resistance of the endotracheal tube (RETT). In early expiration, when the flow is high, RETT considerably increases the time constant. As a consequence of the flow pattern with a peak flow in early expiration and an exponentially declining flow towards the end of expiration, the contribution of RETT is gradually reduced. The time constant of the respiratory system alone, however, increases towards the end of expiration. The combination of these two mechanisms explains that - in the ARDS patients we investigated under uninterrupted mechanical ventilation - the time constant does not change during expiration. If the external resistance of the tubing and ventilator is considered, the "total" time constant of the fast component of passive expiration is about $700 \mathrm{~ms}$, i.e. nearly three times the time constant of the respiratory system alone (fig. 3, lower line). When a ventilatory pattern is chosen so as to achieve the longest possible expiratory time of $3 \mathrm{~s}$ (reduced inspiratory time, no endinspiratory pause), more than $95 \%$ of the expirable volume is already exhaled.

Acknowledgements: The authors gratefully acknowledge the invaluable technical assistance of J. Birle, Augsburg.

\section{References}

1. Milic-Emili J, Zin WA. Relationship between neuromuscular respiratory drive and ventilatory output. In: Macklem PT Mead J, eds. Handbook of Physiology. Section 3. The Respiratory System. Vol. III. Mechanics of Breathing. Part 2; Washington, DC, American Physiological Society, 1986; p. 640.

2. McIlroy MB, Tierney DF, Nadel JA. A new method of measurement of compliance and resistance of lungs and thorax. J Appl Physiol 1963; 18: 424-427. 
3. Zin WA, Pengelly LD, Milic-Emili J. Single-breath method for measurement of respiratory mechanics in anesthetized animals. J Appl Physiol: Respirat Environ Exercise Physiol 1982; 52: 1266-1277.

4. Behrakis PK, Higgs BD, Baydur A, Zin WA, Milic-Emili J. Respiratory mechanics during halothane anesthesia and anesthesia-paralysis in humans. J Appl Physiol: Respirat Environ Exercise Physiol 1983; 55: 1085-1092.

5. Eissa NT, Ranieri VM, Corbeil C, et al. Analysis of the behavior of the respiratory system in ARDS patients: effects of flow, volume and time. J Appl Physiol 1991; 70: 2719-2729.

6. Hoppin FG, Hildebrandt J. Mechanical properties of the lung. In: West $\mathrm{JB}$, ed. Bioengineering Aspects of the Lung. Vol. 3. Lung Biology in Health and Disease. New York, Dekker, 1977; pp. 83-162.

7. Marini JJ, Culver BH, Kirk W. Flow resistance of exhalation valves and positive end-expiratory pressure devices used in mechanical ventilation. Am Rev Respir Dis 1985; 131: 850-854.

8. Perez Fontan JJ, Heldt GP, Targett RC, Willis MM, Gregory GA. Dynamics of expiration and gas trapping in rabbits during mechanical ventilation at rapid rates. Crit Care Med 1986; 14: 39-47.

9. Wright PE, Marini JJ, Bernard GR. In vitro versus in vivo comparison of endotracheal tube airflow resistance. Am Rev Respir Dis 1989; 140: 10-16.

10. Guttmann J, Eberhard L, Fabry B, Bertschmann W, Wolff G. Continuous calculation of intratracheal pressure in tracheally intubated patients. Anesthesiology 1993; 79: 503-513.

11. Bates JHT, Decramer M, Chartrand D, Zin WA, Boddener A, Milic-Emili J. Volume-time profile during relaxed expiration in the normal dog. J Appl Physiol 1985; 59: 732-737.

12. Chelucci GL, Brunet F, Dall'Ava-Santucci J, et al. A single-compartment model cannot describe passive expiration in intubated, paralysed humans. Eur Respir J 1991; 4: 458-464.

13. Chelucci GL, Dall'Ava-Santucci J, Dhainaut J-F, et al. Modelling of passive expiration in patients with adult respiratory distress syndrome. Eur Respir J 1993; 6: 785-790.

14. Ralph DD, Robertson HT, Weaver LJ, Hlastala MP, Carrico CJ, Hudson LD. Distribution of ventilation and perfusion during positive end-expiratory pressure in the adult respiratory distress syndrome. Am Rev Respir Dis 1985; 131: 54-60.

15. Quanjer PT. Documentation of the working group on standardization of lung function tests. Commission of the European Community of Coal and Steel, Luxembourg, 1977.

16. Murray JF, Matthay MA, Luce JM, Flick MR. An expanded definition of the adult respiratory distress syndrome. Am Rev Respir Dis 1988; 138: 720-723.

17. Wolff G, Brunner JX, Weibel W, Bowes CL. Alveolar efficiency for $\mathrm{CO}_{2}$ elimination and series dead space volume, both are affected by the ventilatory pattern. Appl Cardiopulm Pathophysiol 1989; 2: 309-314.
18. Brunner J, Wolff G, Cumming G, Langenstein H. Accurate measurement of $\mathrm{N}_{2}$ volumes during $\mathrm{N}_{2}$ washout requires dynamic adjustment of delay time. J Appl Physiol 1985; 59: 1008-1012.

19. Brunner JX, Wolff G. Pulmonary function indices in critical care patients. Berlin, Heidelberg, New York, London, Paris, Tokyo, Springer, 1988; pp. 26-35.

20. Pepe PE, Marini JJ. Occult positive end-expiratory pressure in mechanically ventilated patients with airflow obstruction. Am Rev Respir Dis 1982; 126: 166170.

21. Eberhard L, Guttmann J, Wolff G, et al. Intrinsic PEEP monitored in the ventilated ARDS patient using a mathematical method. J Appl Physiol 1992; 73: 479-485.

22. Milic-Emili J, Gottfried SB, Rossi A. Dynamic hyperinflation: intrinsic PEEP and its ramifications in patients with respiratory failure. In: Vincent JL, ed. Update in Intensive Care and Emergency Medicine. Berlin, Heidelberg, New York, London, Paris, Tokyo, Springer, 1987; pp. 192-199.

23. Gattinoni L, Pesenti A, Avalli L, Rossi F, Bombino M. Pressure-volume curve of total respiratory system in acute respiratory failure. Am Rev Respir Dis 1987; 136: 730736.

24. Sydow M, Burchardi H, Zinserling J, Ische H, Crozier ThA, Weyland W. Improved determination of static compliance by automated single volume steps in ventilated patients. Intensive Care Med 1991; 17: 108-114.

25. Bertschmann W, Guttmann J, Wolff G. Barotrauma. In: Yacoub M, Pepper JR, eds. Annual of Cardiac Surgery. 6th edn. London, Current Science, 1993; pp. 41-51.

26. Otis $\mathrm{AB}$, McKerrow CB, Bartlett RA, et al. Mechanical factors in distribution pulmonary ventilation. $J \mathrm{Appl}$ Physiol: Respirat Environ Exercise Physiol 1956; 8: 427-443.

27. Bates JHT, Rossi A, Milic-Emili J. Analysis of the behavior of the respiratory system with constant inspiratory flow. J Appl Physiol 1985; 58: 1840-1848.

28. Rossi A, Gottfried SB, Higgs BD, Zocchi L, Grassino A, Milic-Emili J. Respiratory mechanics in mechanically ventilated patients with respiratory failure. $J$ Appl Physiol 1985; 58: 1849-1858.

29. Guttmann J, Eberhard L, Wolff G, Bertschmann W, Zeravik J, Adolph M. Maneuver-free determination of compliance and resistance in ventilated ARDS patients. Chest 1992; 102: 1235-1242.

30. Rossi A, Gottfried SB, Zocchi L, et al. Measurement of static compliance of the total respiratory system in patients with acute respiratory failure during mechanical ventilation: the effect of intrinsic PEEP. Am Rev Respir Dis 1985; 131: 672-677.

31. Broseghini C, Brandolese R, Poggi R, Bernasconi M, Manzin E, Rossi A. Respiratory resistance and intrinsic positive end-expiratory pressure (PEEPi) in patients with the adult respiratory distress syndrome (ARDS). Eur Respir J 1988; 1: 726-731.

32. Bates JHT, Brown KA, Kochi T. Respiratory mechanics in the normal dog determined by expiratory flow interruption. J Appl Physiol 1989; 67: 2276-2285. 